\title{
Interbed Modeling to Predict Wellbore Damage for Big Hill Strategic Petroleum Reserve
}

\author{
Byoung Yoon Park
}

Received: 5 March 2014/ Accepted: 15 March 2014/Published online: 8 May 2014

(C) The Author(s) 2014. This article is published with open access at Springerlink.com

\begin{abstract}
Oil leaks were found in wellbores of Caverns 105 and 109 at the Big Hill Strategic Petroleum Reserve site. According to the field observations, two instances of casing damage occurred at the depth of the interbed between the caprock bottom and salt top. A three-dimensional finite element model, which allows each cavern to be configured individually, was constructed to investigate horizontal and vertical displacements in each well as it crosses the various interbeds. The model contains interfaces between each lithology and a shear zone (fault) to examine the interbed behavior in a realistic manner. This analysis results indicate that the casings of Caverns 105 and 109 failed, respectively, from shear stress that exceeded the casing shear strength due to the horizontal movement of the salt top relative to the caprock and tensile stress due to the downward movement of the salt top from the caprock. The wellbores of Caverns 114 and 104, located at the far end of the field and near the fault, respectively, are predicted to fail by shear stress in the near future. The wellbores of inmost Caverns 107 and 108 are predicted to fail by tensile stress in the near future. The salt top subsides because the volumes of caverns in the salt dome decrease with time due to salt creep closure, while the caprock does not subside at the same rate as the salt top because the caprock is thick and stiff. This discrepancy yields deformation of the well.
\end{abstract}

Keywords Strategic petroleum reserve (SPR) - Salt creep $\cdot$ Wellbore damage · Interbed modeling

B. Y. Park $(\bowtie)$

Geomechanics Department, Sandia National Laboratories, P.O. Box 5800 MS 0751, Albuquerque, NM 87185, USA e-mail: bypark@sandia.gov

$\begin{array}{ll}\text { Abbreviations } \\ \text { 3D } & \text { Three dimensional } \\ \text { BH } & \text { Big Hill } \\ \text { DOE } & \text { Department of Energy } \\ \text { D-P } & \text { Drucker-Prager } \\ \text { FEM } & \text { Finite element method } \\ \text { MMB } & \text { Million barrels } \\ \text { SMF } & \text { Structural multiplication factor } \\ \text { SNL } & \text { Sandia National Laboratories } \\ \text { SPR } & \text { Strategic petroleum reserve } \\ \text { UTM } & \text { Universal transverse } \\ & \text { mercator } \\ \text { WH } & \text { West Hackberry } \\ \text { WIPP } & \text { Waste Isolation Pilot Plant }\end{array}$

\section{List of symbols}

A Power law creep constant

$A_{0} \quad$ Soil and forms model constant

$A_{1} \quad$ Soil and forms model constant

$A_{2} \quad$ Soil and forms model constant

$a \quad \mathrm{D}-\mathrm{P}$ constant

$C \quad$ D-P constant

E Young's modulus

$\dot{\varepsilon} \quad$ Secondary creep strain rate

$I_{1} \quad$ First invariant of the stress tensor

$J_{2} \quad$ Second invariant of the deviatoric stress tensor

$K \quad$ Bulk modulus

$\mu \quad$ Shear modulus

$n \quad$ Stress exponent

$v \quad$ Poisson's ratio

$Q \quad$ Effective activation energy

$R \quad$ Universal gas constant

$\rho \quad$ Density

$\sigma \quad$ Von Mises equivalent stress

$\sigma_{1} \quad$ Maximum principal stress 
$\sigma_{2} \quad$ Intermediate principal stress

$\sigma_{3} \quad$ Minimum principal stress

$\sigma_{\mathrm{m}} \quad$ Mean stress

$T$ Absolute temperature

\section{Background}

The US Strategic Petroleum Reserve (SPR) stores crude oil in 62 caverns located at four different sites in Texas and Louisiana. The reserve currently contains over 700 million barrels (MMB). Most of the caverns were solution mined by the Department of Energy (DOE). Oil leaks were found in the wells of Big Hill (BH) Caverns 105B and 109B by interpreting Caveman ${ }^{1}$ pressure data from Dyn $\mathrm{McDermott}^{2}$ (Ehgartner 2010a, 2011). The Cavern 105B leak started after December 3, 2009, and had progressed to 8,600 bbl on May 14, 2010 before the leak was brought under control by reducing cavern pressure. The rate increased both episodically and exponentially to over $150 \mathrm{bbl}$ per day. The location of the leak is at about $499 \mathrm{~m}$ below the surface, which is close to the interbed between the caprock and the salt dome. The Cavern 109B leak started on October 8, 2010. The total amount of oil leaked is estimated to be $2,700 \mathrm{bbl}$. This occurred over an 88 day period resulting in an average leakage rate of $31 \mathrm{bbl}$ per day. The location of the leak is at the joint in the casing at $497 \mathrm{~m}$ below the surface.

To prevent cavern volume closure due to salt creep, a wellhead pressure of 6.24 MPa (905 psi) is applied when the caverns are at normal or static conditions. This added pressure, along with the hydrostatic pressure of the stored oil, is enough to counteract the lithostatic pressure of the salt-producing creep. A leak at the interbed may inject a large amount of oil into the discontinuity (or "fault") or layer (or "seam") making up the interbed. The leaked oil could flow out past the dome boundary to the surrounding rocks and/or into nearby aquifers. This could be a significant source of environmental contamination. The leaking oil would also cause a decrease in the wellhead pressure. The accompanying loss in cavern pressure would allow the surrounding salt to creep into the cavern and its closure rate to increase unacceptably.

\section{Approach}

This paper attempts to find causes of the leaks through using numerical analysis. Previous three-dimensional finite

\footnotetext{
1 Cavern pressure monitoring program developed by Sandia National Laboratories (SNL).

2 Petroleum Operations Company of New Orleans to maintain the readiness of the SPR's four crude oil storage facilities in Louisiana and Texas.
}

element analyses were performed to evaluate the structural integrity of SPR caverns located in BH salt dome (Park et al. 2006). The cavern field was simplified using a 30-degree wedge model. The wedge model did not contain the interfaces between lithologies around the salt dome and the fault (shear zone) that cuts across the overburden and caprock layers. The advanced model in this paper is a full $3 \mathrm{D}$ rendering of the site and includes the lithologic interfaces and the fault needed to simulate motion between the caprock and the salt dome. The new model developed in this study considers actual geometries and locations of 14 SPR caverns and salt dome interfaces between the overburden and caprock, 2 caprock lithologies, caprock and salt dome, dome and surrounding rock, and a shear zone in the overburden and caprock layers. The shear displacement and vertical strain above the center of each cavern in the interbed between caprock and salt dome will be calculated and compared to the field data. The evolution of the shear displacement and vertical strain will be investigated.

\section{Model Description}

\subsection{Geomechanical Model}

\subsubsection{Salt Dome Geometry}

Figure 1 shows a plan view of the $\mathrm{BH}$ site with contour lines defining the approximate location of the salt dome top. The locations for the 14 SPR caverns currently in use (101-114) and 5 potential expansion caverns (X1-5) are

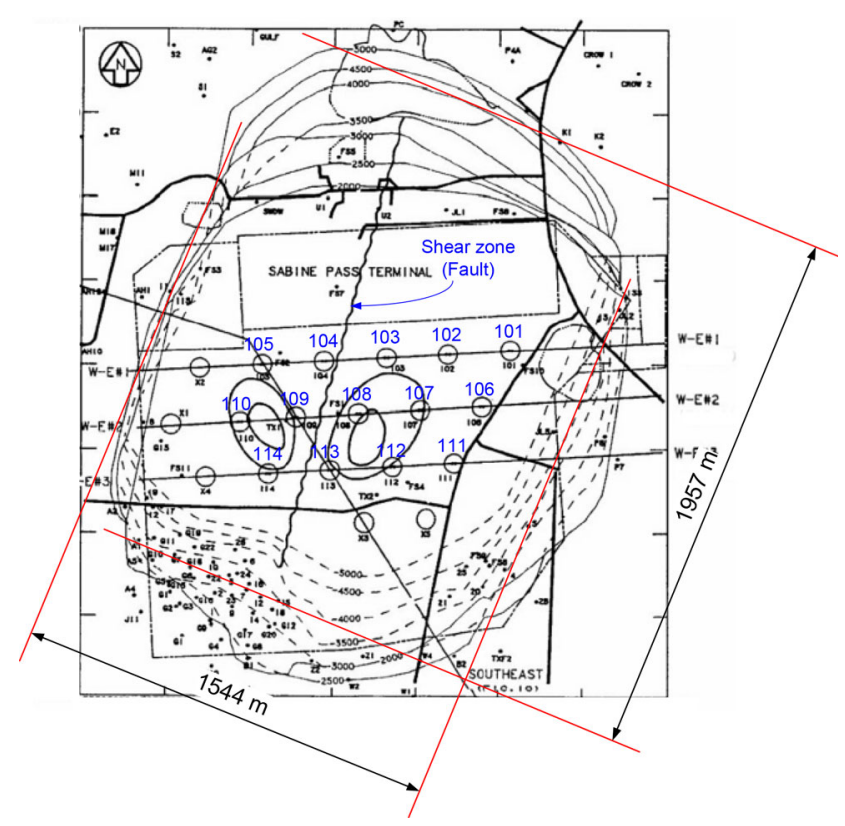

Fig. 1 Big Hill site plan view (Magorian and Neal 1988) 


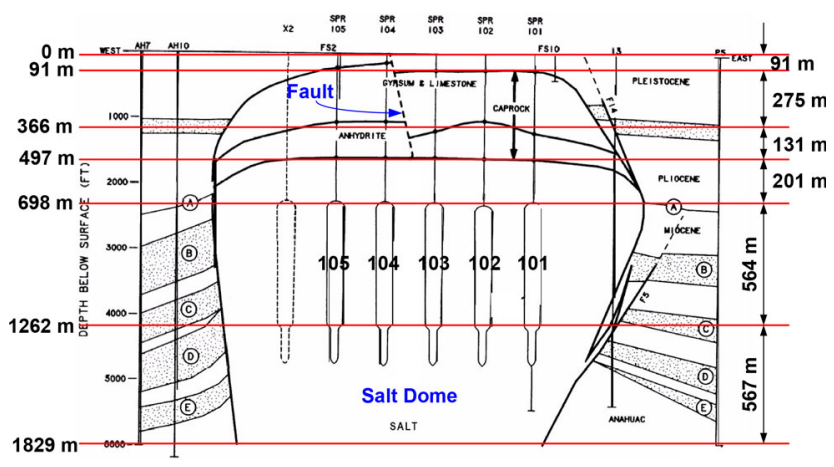

Fig. 2 Cross section (W-E \#1 in Fig. 1) near the middle of the dome (Magorian and Neal 1988)

shown. The figure also indicates the undeveloped area north of the DOE property line (Sabine Pass Terminal). The horizontal shape of the dome is approximately elliptical. The major and minor ellipse axes are measured as 1,957 and $1,544 \mathrm{~m}$, respectively.

The west-east cross-section \#1 through the northernmost row of caverns (Caverns 101-105) provides a geologic representation near the middle of the dome (Fig. 2). The site has a thin overburden layer consisting of sandy soil and an exceptionally thick caprock sequence comprising two layers. The upper caprock comprised mainly of gypsum and limestone, whereas the lower caprock is mostly anhydrite. A major fault extends approximately north-south along the entire length of the caprock and for an unknown depth into the salt. This fault zone has a pronounced effect on the subsidence measured above the site and is a consideration for future cavern placement (Ehgartner and Bauer 2004).

For analysis purposes, the top layer of overburden is modeled as having a thickness of $91 \mathrm{~m}$, the upper caprock $275 \mathrm{~m}$ thick, and the lower caprock $131 \mathrm{~m}$ thick. The salt thickness over the caverns is approximately $201 \mathrm{~m}$. The bottom boundary of the present analysis model is set at $1,829 \mathrm{~m}$ below the surface.

\subsubsection{Salt Constitutive Model and Parameter Values}

Data for the creep constant, the stress exponent, and the thermal constant for the power law creep model used to describe the geomechanical behavior of the $\mathrm{BH}$ salt are very limited. Where needed, the data from the West Hackberry (WH) site has been used to augment the $\mathrm{BH}$ data, since both BH and WH salts are classified as soft salts (Munson 1998) and are assumed to be mechanically similar for the purpose of this study. The salt data were derived through mechanical property testing of salt cores collected from boreholes (Wawersik and Zeuch 1984). The creep
Table 1 Material properties of Big Hill salt used in the analysis

\begin{tabular}{|c|c|c|c|}
\hline Parameter & Unit & Value & References \\
\hline Young's modulus $(E)$ & $\mathrm{GPa}$ & 31 & Krieg( 1984) \\
\hline Density $(\rho)$ & $\mathrm{kg} / \mathrm{m}^{3}$ & 2,300 & Krieg (1984) \\
\hline Poisson's ratio $(v)$ & - & 0.25 & Krieg (1984) \\
\hline Bulk modulus $(K)$ & $\mathrm{GPa}$ & 20.67 & Using $E, v$ \\
\hline Shear modulus $(\mu)$ & $\mathrm{GPa}$ & 12.40 & Using $E, v$ \\
\hline Creep constant $(A)$ & $\mathrm{Pa}^{-4.9} / \mathrm{s}$ & $5.79 \times 10^{-36}$ & Krieg (1984) \\
\hline $\begin{array}{l}\text { Structure } \\
\text { multiplication factor } \\
(S M F)\end{array}$ & - & 1.5 & $\begin{array}{l}\text { Park et al. } \\
\text { (2005) }\end{array}$ \\
\hline $\begin{array}{l}\text { Calibrated creep } \\
\text { constant }\end{array}$ & $\mathrm{Pa}^{-4.9} / \mathrm{s}$ & $8.69 \times 10^{-36}$ & $\begin{array}{l}\text { Park et al. } \\
\quad(2005)\end{array}$ \\
\hline Stress exponent $(n)$ & - & 4.9 & Krieg (1984) \\
\hline Thermal constant $(Q)$ & $\mathrm{cal} / \mathrm{mol}$ & 12,000 & Krieg 1984) \\
\hline $\begin{array}{r}\text { Universal gas } \\
\text { constant }(R)\end{array}$ & $\mathrm{cal} /(\mathrm{mol} \mathrm{K})$ & 1.987 & $\begin{array}{l}\text { Mohr et al. } \\
\text { (2011) }\end{array}$ \\
\hline $\begin{array}{l}\text { Input thermal constant } \\
(Q / R)\end{array}$ & $\mathrm{K}$ & 6,039 & $\begin{array}{l}\text { Using } Q \text { and } \\
\quad R\end{array}$ \\
\hline
\end{tabular}

constitutive model considers only secondary or steady-state creep. The creep strain rate is determined from the effective stress as follows:

$\dot{\varepsilon}=A\left(\frac{\sigma}{\mu}\right)^{n} \exp \left(-\frac{Q}{R T}\right)$

where $\dot{\varepsilon}=$ secondary creep strain rate; $\sigma=$ von Mises equivalent stress; $\mu=$ shear modulus $=E / 2(1+v)$, where $E$ is Young's modulus and $v$ is Poisson's ratio; $T=$ absolute temperature; $A=$ power law creep constant determined from back-fitting the model to creep data; $n=$ stress exponent; $Q=$ effective activation energy; $R=$ universal gas constant.

The creep constant, $A$, in Eq. (1) is adjusted by a structural multiplication factor (SMF) which is used to match the volumetric closure of caverns. Through a number of back-fitting analyses (Park et al. 2005), a calibrated power law creep constant was determined. The values used as input data in the present analyses are listed in Table 1 .

\subsubsection{Lithologies Around the Salt Dome}

The surface overburden layer, which mostly comprised sandy soil, is modeled as exhibiting linear elastic material behavior. The layer is considered isotropic and has no assumed failure criteria. The upper caprock layer, consisting of gypsum and limestone, is also assumed to be linear elastic. Its properties are taken to be the same as those used for the WH analyses (Ehgartner and Sobolik 2002). The rock surrounding the salt dome is assumed to be isotropic, homogeneous, linear elastic sandstone. 
Table 2 Material properties of lithologies around salt dome used in the analyses

\begin{tabular}{llllll}
\hline Parameters & Unit & Overburden & Caprock 1 & Caprock 2 & Surrounding rock \\
\hline Young's modulus $(E)$ & $\mathrm{GPa}$ & 0.1 & 21 & 75.1 & 70 \\
$\begin{array}{l}\text { Density }(\rho) \\
\text { Poisson's ratio }(v)\end{array}$ & $\mathrm{kg} / \mathrm{m}^{3}$ & 1,874 & 2,500 & 2,300 & 2,500 \\
Drucker-Prager constants & - & 0.33 & 0.29 & 0.35 & 0.33 \\
$C$ & $\mathrm{MPa}$ & $\mathrm{N} / \mathrm{A}$ & $\mathrm{N} / \mathrm{A}$ & 1.35 & \\
$a$ & - & N/A & N/A & 0.45 & N/A \\
Bulk modulus $(\mathrm{K})$ & $\mathrm{GPa}$ & N/A & N/A & 83.44 & N/A \\
Shear modulus $(\mu)$ & $\mathrm{GPa}$ & N/A & N/A & 27.82 & N/A \\
Soil and forms model constants & & & & \\
$A_{0}$ & $\mathrm{MPa}$ & N/A & N/A & 2,338 & N/A \\
$A_{1}$ & - & N/A & N/A & 2.338 & N/A \\
$A_{2}$ & - & N/A & N/A & 0 & N/A \\
\hline
\end{tabular}

The anhydrite in the lower caprock layer is expected to experience inelastic material behavior. The anhydrite layer is considered isotropic and elastic until yield occurs (Butcher 1997). Once the yield stress is reached, plastic strain begins to accumulate. Yield is assumed to be governed by the Drucker-Prager (D-P) criterion:

$\sqrt{J_{2}}=C-a I_{1}$

where $I_{1}=\sigma_{1}+\sigma_{2}+\sigma_{3}=3 \sigma_{m}$ : the first invariant of the stress tensor; $\sqrt{J_{2}}=\sqrt{\frac{\left(\sigma_{1}-\sigma_{2}\right)^{2}+\left(\sigma_{2}-\sigma_{3}\right)^{2}+\left(\sigma_{3}-\sigma_{1}\right)^{2}}{6}}$ : the square root of the second invariant of the deviatoric stress tensor; $\sigma_{1}, \sigma_{2}$, and $\sigma_{3}$ are the maximum, intermediate, and minimum principal stresses, respectively; $\sigma_{m}$ is the mean stress; and $C$ and $a$ are D-P constants.

Again, the material properties of the $\mathrm{BH}$ anhydrite are not known. Therefore, the behavior of the BH anhydrite is assumed to be the same as the Waste Isolation Pilot Plant (WIPP) anhydrite. A non-associative flow rule is used to determine the plastic strain components. A soils and foams model $^{3}$ is used for the lower caprock. The input parameters, $A_{0}, A_{1}$ and $A_{2}$, are derived from the elastic properties and the D-P constants, $C$ and $a$ (Park et al. 2006).

The material properties for the lithologies overlying and surrounding the $\mathrm{BH}$ salt dome used as input data for the two SNL-developed 3D solid mechanics codes used in the present analyses, JAS3D ${ }^{4}$ and Adagio, ${ }^{5}$ are listed in Tables 1 and 2.

\subsubsection{Interfaces and Fault Model}

To investigate causes of well casing damage between the salt dome and the caprock, horizontal shear displacements

\footnotetext{
3 The soils and foams model is a volumetric cap plasticity model developed by SNL.

${ }^{4}$ JAS3D is a three-dimensional (3D) iterative solid mechanics code developed by SNL.

5 Adagio is the most recently SNL-developed 3D solid mechanics code. It is written for parallel computing environments.
}

and vertical strains at the interbed need to be examined. Thus, interface blocks, special purpose analysis tools, are used to represent the interfaces between Caprock 1 and Caprock 2; Caprock 2 and salt dome; surrounding rock and dome. The material behavior away from the interbed is represented by material properties of Caprock 1, Caprock 2 , and salt. The fault, which was ignored for the simplification in previous analyses (Park et al. 2005), is included in this model to perhaps better represent the large-scale deformation considered in this study.

Adagio has a contact surface algorithm for modeling contact and sliding behavior between two solid surfaces. However, this algorithm has a limitation on the number of elements in the model. The current model is over the limitation. In place of a contact surface, a thin soft layer of elements is used for the interface between lithologies. The thin soft element layer uses the overburden material properties and is assumed to behave mechanically like a contact surface with the friction coefficient of 0.2 from a perspective of relative displacement between two lithologies. Thus, the overburden material properties (Table 2) are used in the analysis for the interfaces and fault layers.

The thickness of the fault varies from a millimeter to a hundred meters with fault displacement (Fig. 3). In this study, the thickness of the interface material is assumed to be a uniform $4.3 \mathrm{~m}$, based on the measured largest thickness of the salt/caprock interbed from a Weatherford multiarm caliper survey data (Wynn 2012). These model attributes incorporated into the finite element method (FEM) mesh will be described in Sect. 4 .

\subsection{Cavern Model}

\subsubsection{Cavern Geometry and Layout}

The cavern shapes are approximately cylindrical and the cavern array is regular as shown in Fig. 4. The cavern 


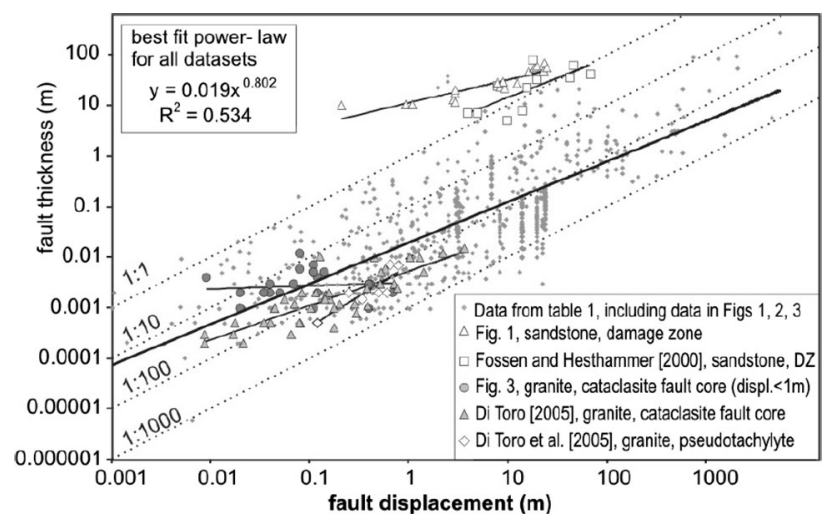

Fig. 3 Log-log plot of a compilation of 16 fault thickness datasets reported in the literature including the data used by Hull (1988), and the three datasets in Shipton et al. (2006)

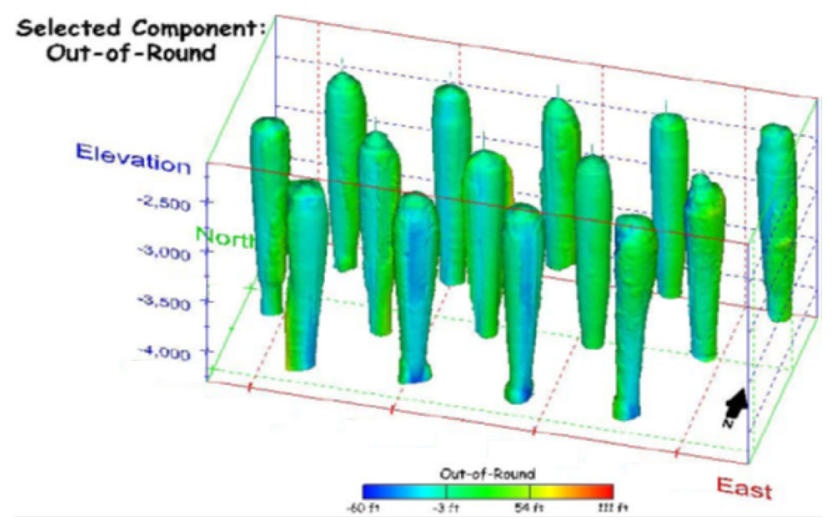

Fig. 4 Perspective view of the entire cavern field at the Big Hill SPR site from the southeast (Rautman and Lord 2007). Elevation unit is feet

dimensions used in the model are simplified and are listed in Table 3 based on sonar data. The completion date for the initial leach of each cavern is also listed. The $\mathrm{X}$ - and Y-coordinates for the center of each cavern were calculated by subtracting the universal transverse mercator (UTM) coordinates of the center of the dome from UTM coordinates of each cavern. That is, the origin for the coordinate system of the model is the center of the dome.

\subsubsection{Model History}

The caverns were leached from April 1990 through August 1991 as listed in Table 3. To investigate the cause of oil leaks and evaluate the other casings at the site, the slick well casing above the caverns were recently inspected with Weatherford multi-arm caliper. The leak date of Cavern 109 is regarded as the baselines of vertical and horizontal strains, respectively, in this simulation. For example, July 24, 1990, when the Cavern 109 leach was completed, is 242.66 months (21.22 years) before October 8, 2010, when the oil leak occurred at Well 109. The simulation results will be generated every month, i.e., the smallest output time unit is month. 242.66 months can be rounded off to 243 months ( 21.25 years) which is calculated to be July 13, 1990. Thus, the leach completion date of Cavern 109 is assumed to be July 13, 1990 rather than July 24, 1990 (actual date). To simplify the model history for the purposes of the present simulation, it is assumed that all existing caverns were initially leached in July 13 1990, which is the leach completion date of Cavern 109 and considered time $t=1$ year in the simulation. The analysis simulates caverns that were leached to full size over a 1-year period by means of gradually switching from salt to freshwater in the caverns. It was assumed that the SPR caverns were filled with petroleum 1 year after their initial leaches start. The caverns are simulated as creeping for 50 years. Figure 5 shows the time sequence for this study of the BH site.

The pressure condition applied to each cavern is based on an average wellhead pressure of $6.24 \mathrm{MPa}$ (905 psi) which occurs when the wells are operated at normal or static conditions. An analysis of cavern pressures at $\mathrm{BH}$ between the years 1990 and 2010 indicates a cavern is pressurized within its normal operating range $74.0 \%$ of the time (1,351 days during each 5-year period between drawdown leaches). Other operations, such as fluid transfers and workovers, ${ }^{6}$ require lower cavern pressures. Therefore, pressure drops are periodically included to simulate times during workover conditions. For simulation purposes, the pressure drop to $0 \mathrm{psi}$ within each cavern lasts for 3 months which is about $4.9 \%$ of the time (89 days) during each 5-year period (Ehgartner 2010a, b). Rather than complicating the analyses, the following assumptions were made for the workover scenario. To better simulate actual field conditions, not all caverns are in workover mode at the same time. The oil drawdowns ${ }^{7}$ are not considered in this simulation. The simulation is conducted for 51 years. Figure 6 shows the wellhead pressure histories for each cavern. For workover conditions, the wellhead pressure is dropped to zero. The workover durations are 3 months for all caverns. This workover cycle is repeated every 5 years. For both normal and workover conditions, the caverns and wellbore are assumed to be full of oil having a pressure gradient of $8,370 \mathrm{~Pa} / \mathrm{m}(0.37 \mathrm{psi} / \mathrm{ft})$ of depth. The pressure due to the oil head plus the wellhead is applied on the cavern and wellbore boundary during the normal operation. Creep closure is allowed to occur in all caverns during the simulation period.

\footnotetext{
6 "Workover" is when the wellhead pressure in the cavern is dropped to zero for maintenance.

7 "Drawdown" is when the crude oil is withdrawn from the cavern. Freshwater is used to withdraw the crude oil. Because the cavern enlarges due to salt dissolving from the cavern walls, it is called a "drawdown leach".
} 
Table 3 Geometric parameters and initial leach completion dates for the 14 extant caverns

\begin{tabular}{lrllllllll}
\hline $\begin{array}{l}\text { Cavern } \\
\text { ID }\end{array}$ & $\begin{array}{l}\text { X (east) } \\
(\mathrm{m})\end{array}$ & $\begin{array}{l}\text { Y (north) } \\
(\mathrm{m})\end{array}$ & $\begin{array}{l}\text { Z (vertical } \\
\text { center) }(\mathrm{m})\end{array}$ & $\begin{array}{l}\text { Diameter } \\
(\mathrm{m})\end{array}$ & $\begin{array}{l}\text { Radius } \\
(\mathrm{m})\end{array}$ & $\begin{array}{l}\text { Cavern } \\
\text { top }(\mathrm{m})\end{array}$ & $\begin{array}{l}\text { Cavern } \\
\text { bottom }(\mathrm{m})\end{array}$ & $\begin{array}{l}\text { Cavern } \\
\text { height }(\mathrm{m})\end{array}$ & $\begin{array}{l}\text { Leach done date } \\
(\mathrm{mm} / \mathrm{dd} / \mathrm{yyyy})\end{array}$ \\
\hline 101 & 571.5 & -167.9 & -979.9 & 67.1 & 33.5 & -698 & $-1,262$ & 563.9 & $9 / 18 / 1990$ \\
102 & 342.9 & -167.9 & -979.9 & 67.1 & 33.5 & -698 & $-1,262$ & 563.9 & $10 / 21 / 1990$ \\
103 & 114.3 & -167.9 & -979.9 & 67.1 & 33.5 & -698 & $-1,262$ & 563.9 & $11 / 28 / 1990$ \\
104 & -114.3 & -167.9 & -979.9 & 67.1 & 33.5 & -698 & $-1,262$ & 563.9 & $10 / 21 / 1990$ \\
105 & -342.9 & -167.9 & -979.9 & 67.1 & 33.5 & -698 & $-1,262$ & 563.9 & $11 / 11 / 1990$ \\
106 & 457.2 & -365.8 & -979.9 & 67.1 & 33.5 & -698 & $-1,262$ & 563.9 & $10 / 16 / 1990$ \\
107 & 228.6 & -365.8 & -979.9 & 67.1 & 33.5 & -698 & $-1,262$ & 563.9 & $4 / 24 / 1990$ \\
108 & 0.0 & -365.8 & -979.9 & 67.1 & 33.5 & -698 & $-1,262$ & 563.9 & $6 / 14 / 1990$ \\
109 & -228.6 & -365.8 & -979.9 & 67.1 & 33.5 & -698 & $-1,262$ & 563.9 & $7 / 24 / 1990$ \\
110 & -457.2 & -365.8 & -979.9 & 67.1 & 33.5 & -698 & $-1,262$ & 563.9 & $4 / 19 / 1990$ \\
111 & 342.6 & -563.6 & -979.9 & 67.1 & 33.5 & -698 & $-1,262$ & 563.9 & $7 / 15 / 1991$ \\
112 & 114.0 & -563.9 & -979.9 & 67.1 & 33.5 & -698 & $-1,262$ & 563.9 & $6 / 19 / 1991$ \\
113 & -114.6 & -563.6 & -979.9 & 67.1 & 33.5 & -698 & $-1,262$ & 563.9 & $5 / 1 / 1991$ \\
114 & -343.2 & -563.6 & -979.9 & 67.1 & 33.5 & -698 & $-1,262$ & 563.9 & $8 / 29 / 1991$
\end{tabular}

Fig. 5 Time sequence for the simulation
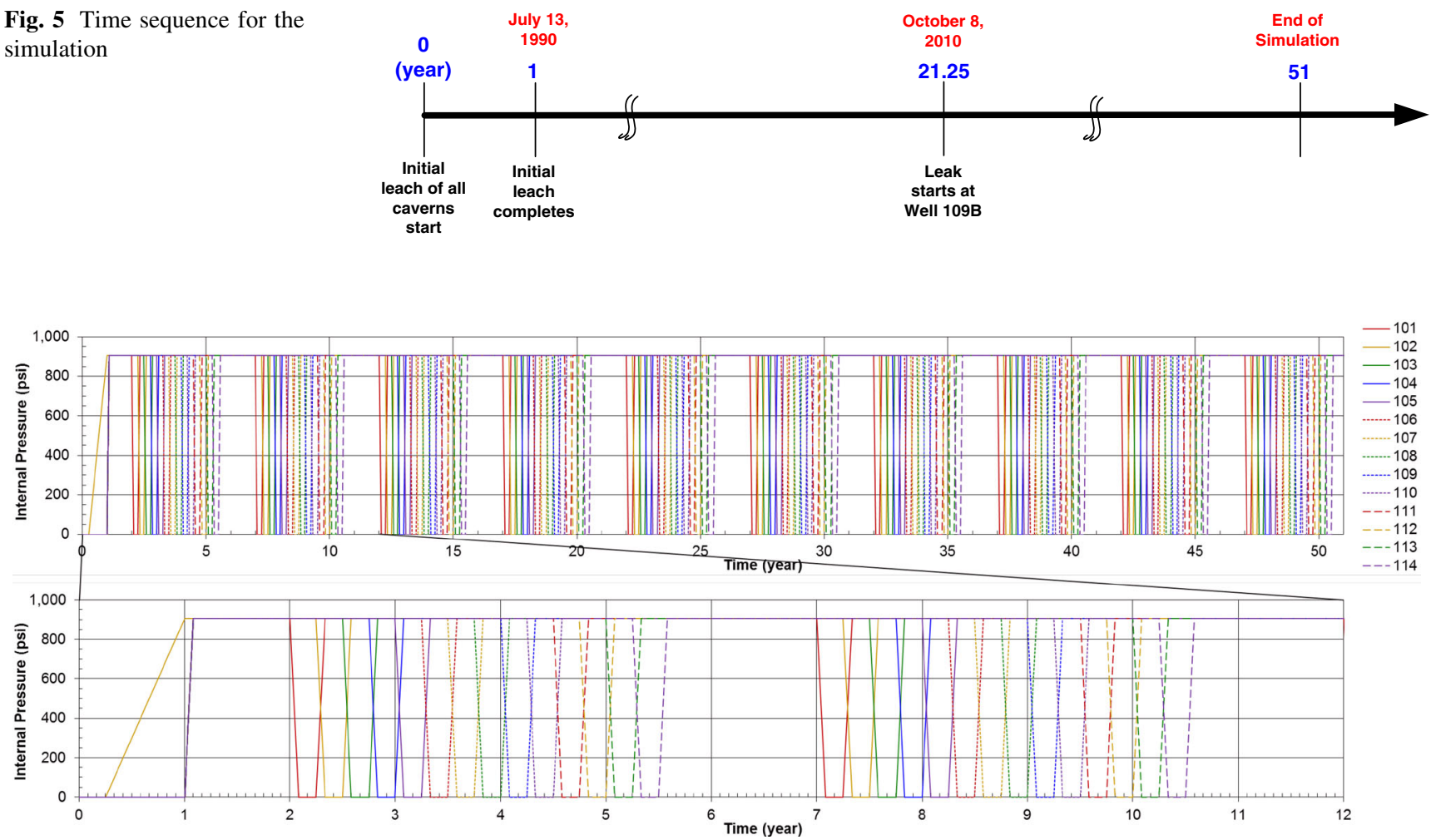

Fig. 6 Wellhead pressure change in each cavern as a function of time

\section{Workover scenario}

- A constant pressure (6.24 MPa) indicating a normal condition is applied for the majority of the time (Fig. 6).

- For workover conditions, the wellhead pressure is dropped to zero.
- Workover of Cavern 101 begins 1 year after the initial leach is completed. After that, workovers are performed on Caverns 102 through 114 in numerical order. Workovers begin as soon as the workover of the prior cavern is completed.

- Workover durations are 3 months for all caverns. 


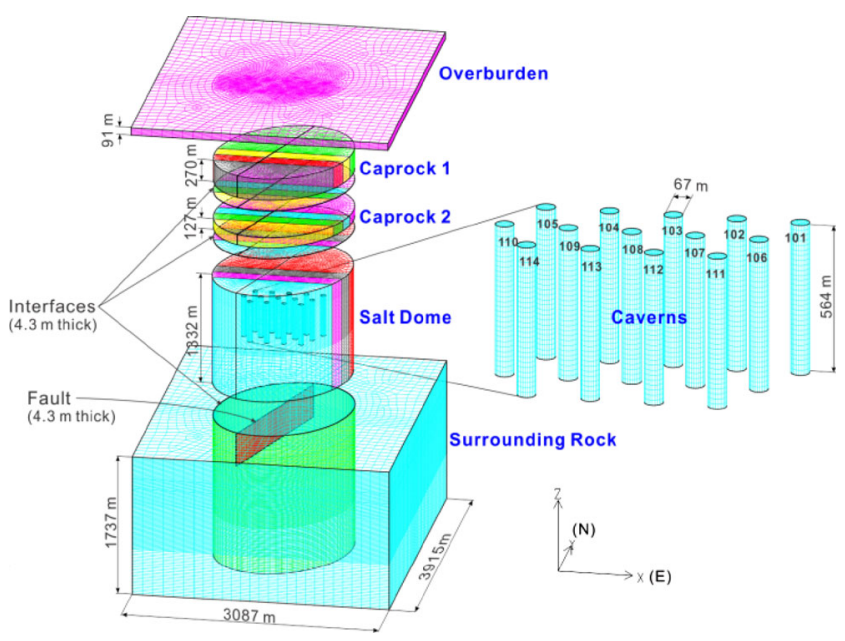

Fig. 7 Overview of the finite element mesh of the stratigraphy and cavern field at Big Hill

- This workover cycle is repeated every 5 years.

- For both normal and workover conditions, the caverns are assumed to be full of oil having a pressure gradient of $8,370 \mathrm{~Pa} / \mathrm{m}$ of depth.

- Pressure due to the oil head plus the wellhead is applied on the cavern boundary during the normal operation.

\subsection{Thermal Conditions}

The finite element model includes a depth-dependent temperature gradient which starts at $24.84^{\circ} \mathrm{C}\left(76.7^{\circ} \mathrm{F}\right)$ at the surface and increases at the rate of $2.57{ }^{\circ} \mathrm{C} / 100 \mathrm{~m}$ $\left(1.41^{\circ} \mathrm{F} / 100 \mathrm{ft}\right)$. The temperature profile is based on the average temperature data recorded in well logs from $\mathrm{BH}$ prior to leaching (Ballard and Ehgartner 2000). The temperature distribution is important because the creep response of the salt is temperature dependent. Radial temperature gradients due to cavern cooling effects from the cavern contents are not considered in these calculations. Previous 2D cavern studies have shown the predicted cavern deformation to be insensitive to the developed radial thermal gradients (Hoffman 1992).

\section{Mesh}

A three-dimensional mesh, which allows each cavern to be configured individually, was constructed to investigate shear displacements and vertical strains in the interbed. Figure 7 shows the overview of the finite element mesh of the stratigraphy and cavern field at BH. The mesh has been separated to show the individual material blocks. The $X$ axis of the model is in the east direction, $Y$-axis is along the north direction, and $Z$-axis is the vertical direction, with

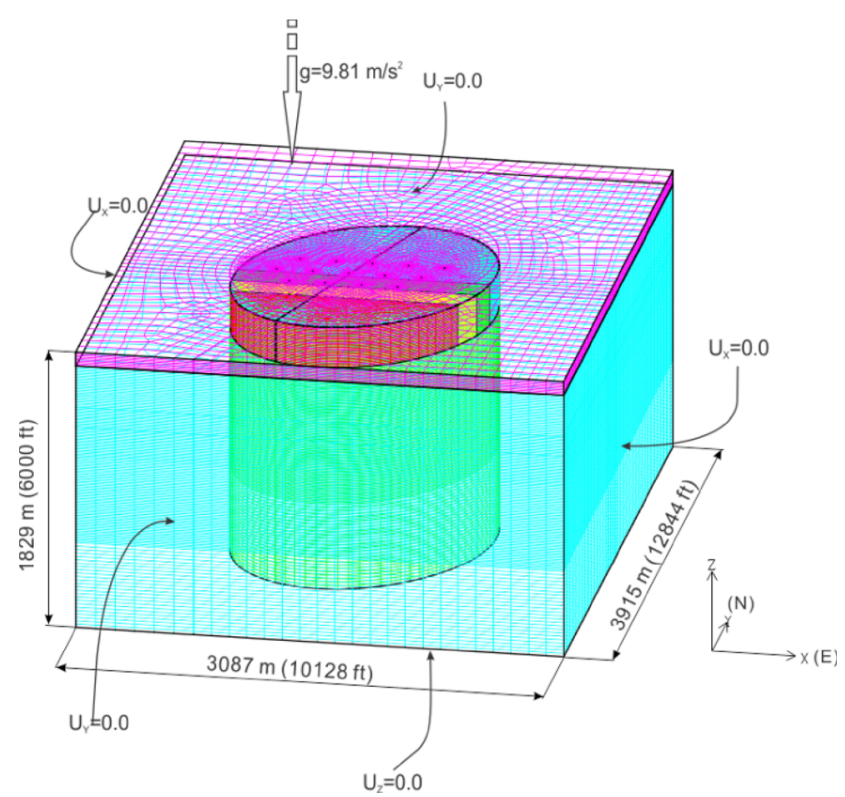

Fig. 8 Finite element mesh discretization and boundary conditions at Big Hill SPR site

upward being positive. The mesh consists of nine material blocks. Five material blocks are used for Overburden, Caprock 1, Caprock 2, salt dome, and surrounding rock. Three material blocks are used for the interfaces, and one material block is used for the fault. Fourteen cavern spaces exist inside the salt dome block to represent the cavern volumes. All caverns are idealized as cylinders $563.9 \mathrm{~m}$ in height with $67.1 \mathrm{~m}$ diameter. The top of caverns is $201.2 \mathrm{~m}$ downward away from the top of salt $(698.0 \mathrm{~m}$ below the surface).

The surrounding rock block encircles Caprock 1, Caprock 2 , and salt dome. The interbed under Caprock 1 block is split off from it; thus the thickness of Caprock 1 block becomes $270.7 \mathrm{~m}(=275-4.3 \mathrm{~m})$. The interbed under Caprock 2 block is split off from it; thus the thickness of Caprock 2 block becomes $126.7 \mathrm{~m}$. The interface surrounding Caprock 1 , Caprock 2, and salt dome is split off from the inside of the surrounding rock block; thus the radii of Caprock1, Caprock 2 , and salt dome are not changed, but the inside radius of surrounding rock increases by $4.3 \mathrm{~m}$.

Figure 8 shows the assembled mesh and the boundary conditions. The salt dome is modeled as being subjected to a regional far-field stresses acting from an infinite distance away. The lengths of the confining boundaries are 3,915 m (two times the dome's major diameter) in the $\mathrm{N}-\mathrm{S}$ direction and 3,087 $\mathrm{m}$ (two times the dome's minor diameter) in the E-W direction. The mesh consists of 877,134 nodes and 861,369 elements with 26 element blocks, 5 node sets, and 14 side sets. The mesh was created using CUBIT $^{8}$ version 13.1.

$\overline{8}$ A mesh generation software copyrighted by Sandia Corporation. 
Fig. 9 Realization of the dome as the FEM mesh

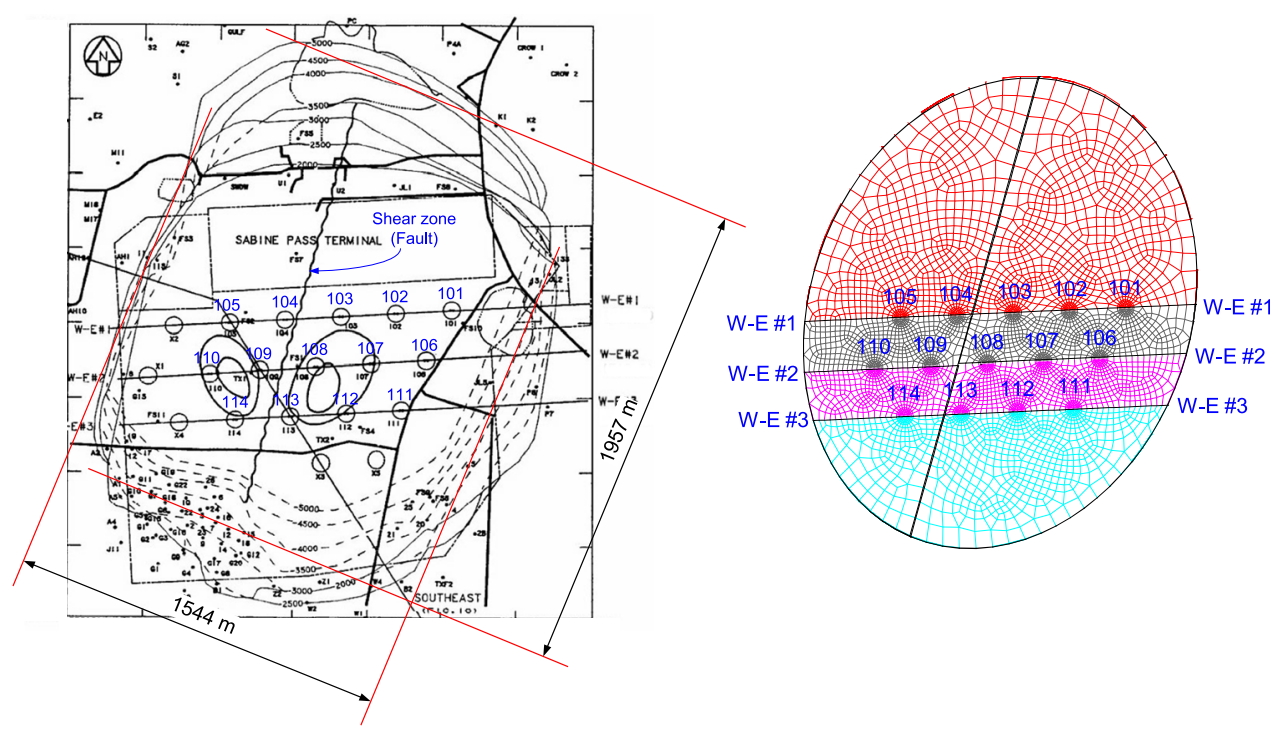

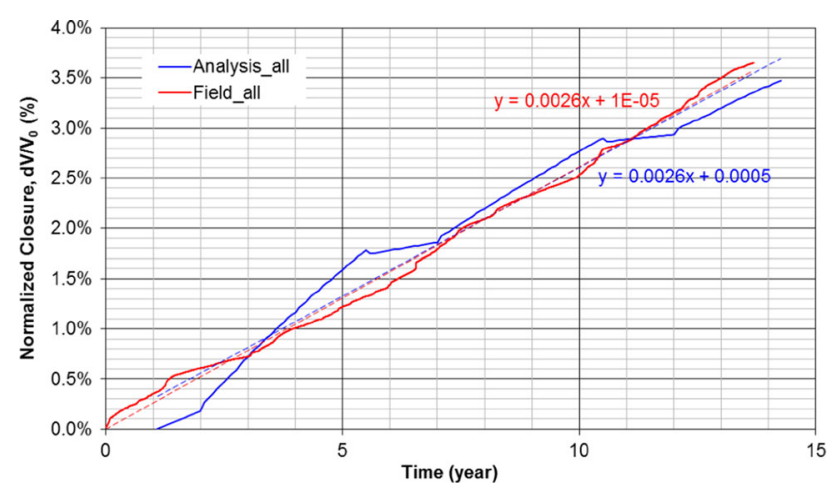

Fig. 10 Comparison of predicted total volumetric closure normalized by total initial volume of the 14 caverns with the field data

The interior of the model consists of material blocks salt dome, Caprock 1, and Caprock 2. It is idealized as an elliptical cylinder with its $1,957 \mathrm{~m}(6,422 \mathrm{ft})$ major diameter in the $\mathrm{N}-\mathrm{S}$ direction, $1,544 \mathrm{~m}(5,064 \mathrm{ft})$ minor diameter in the $\mathrm{E}-\mathrm{W}$ direction, and of $1,737 \mathrm{~m}$ height $(1,332 \mathrm{~m}$ salt dome height). The dome ellipse blocks are rotated clockwise $22.5^{\circ}$ to realize the salt dome as shown in Fig. 9 . To see the cross section of caverns easily, each dome and interface block is divided by four element blocks. Three cross sections correspond to the ease-west cross sections $\# 1$, \#2, and \#3 in Fig. 1.

The thickness of the fault (shear zone) is also assumed to be $4.3 \mathrm{~m}$. The strike direction and dip of the fault are $\mathrm{N} 18^{\circ}$ $\mathrm{E}$ and $90^{\circ}$, respectively. The strike direction was approximated as shown in Fig. 9, and the dip was assumed to be vertical for the simplification. The fault runs between Caverns 103 and 104, Caverns 108 and 109, and Caverns 113 and 114. The fault is assumed to extend down to the top of salt dome from the surface.

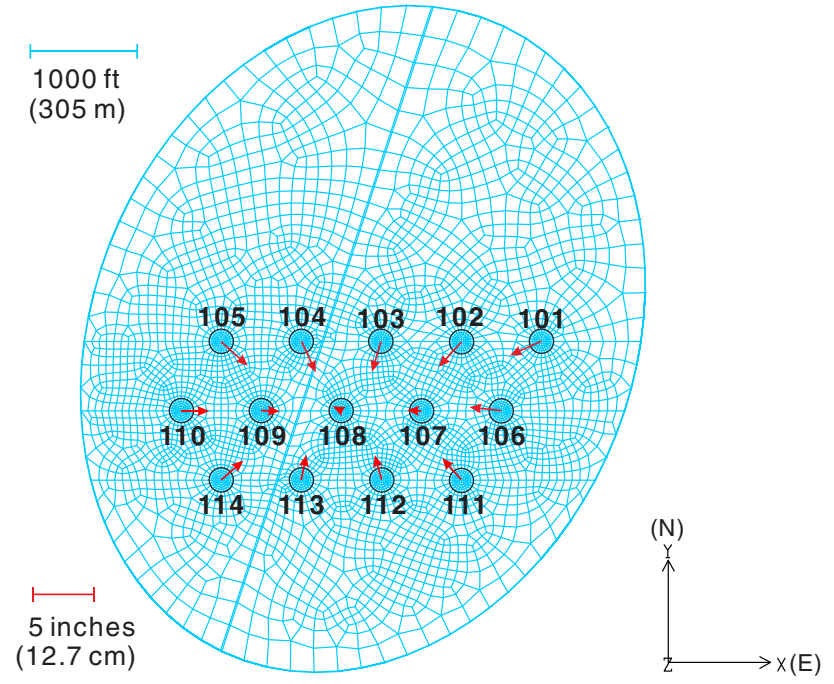

Fig. 11 Direction and magnitude of horizontal movement on the salt top above the center of each cavern at 20.42 years simulation time

\section{Model Verification}

Figure 10 shows the comparison of the simulated volumetric closure of 14 caverns normalized by the 14 initial cavern volumes (i.e., cavern volume strain) with the field data. The slopes of the trend lines from the analysis and field are almost the same at 0.0026 , i.e., the modeled volume closure rates match the field data fairly well. A discrepancy between the analysis results and the field data occurs because the workover history for each cavern in the analysis is idealized with the 5-year period. The predicted total volumetric closure normalized by total initial volume of 14 caverns matches the field data well. This model approximation is reasonable to use to investigate the interbed behavior because it is judged to represent the gross 


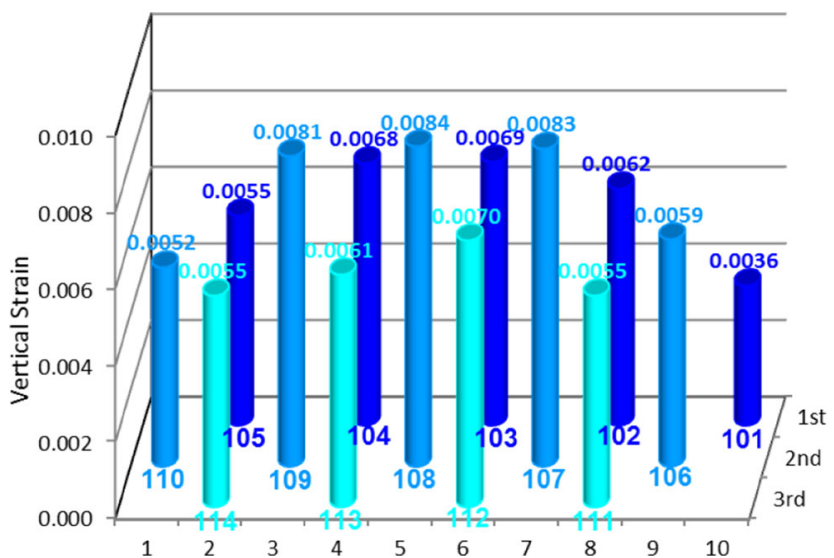

Fig. 12 Vertical strain in the interbed between Caprock 2 and salt dome above the center of each cavern at 21.25 years simulation time

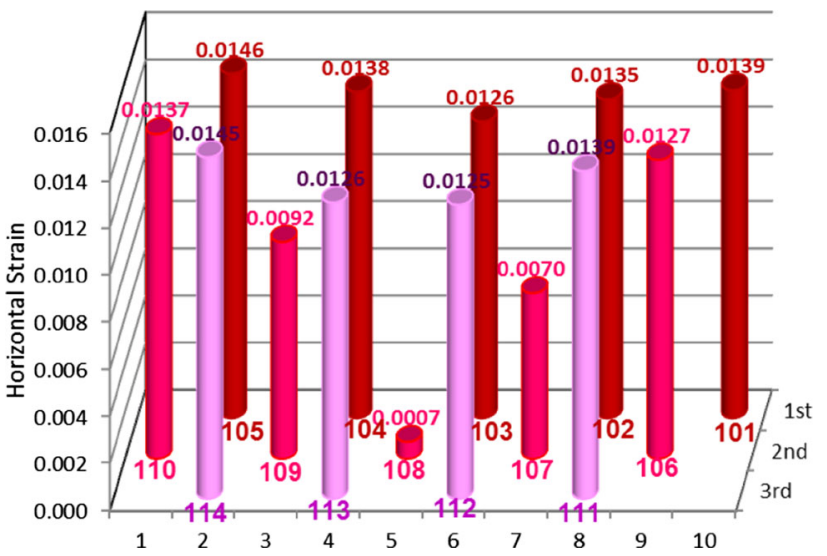

Fig. 13 Horizontal strain between Caprock 2 bottom and salt dome top above the center of each cavern at 20.42 years simulation time

volume closure (strain) rather well. It is hypothesized that well casing damage at the interbed would be caused by large-scale salt rock mass movements brought about by cavern volume closure due to salt creep.

\section{Analysis Results}

\subsection{At Oil Leak Dates of Well 105 and 109}

Horizontal strains in the interbed between Caprock 2 and salt dome above the center of each cavern are calculated at year $t=20.42$, which is 19.42 years after the initial leach is completed and represents the Well 105 leak date of December 32009 calendar year. Vertical strains in the interbed between Caprock 2 and salt dome above the center of each cavern are calculated at year $t=21.25$, which is 20.25 years after the initial leach is completed and represents the Well 109 leak date of October 82010 calendar year. The bottom of Caprock 2 and the top of salt dome $\uparrow N$

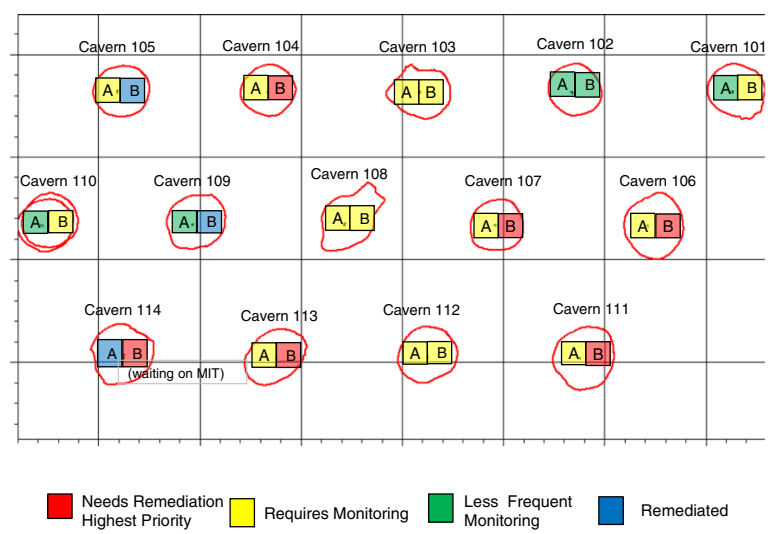

Fig. 14 Big Hill caverns aerial view with Multi-Arm Caliper survey classification (Wynn 2012)

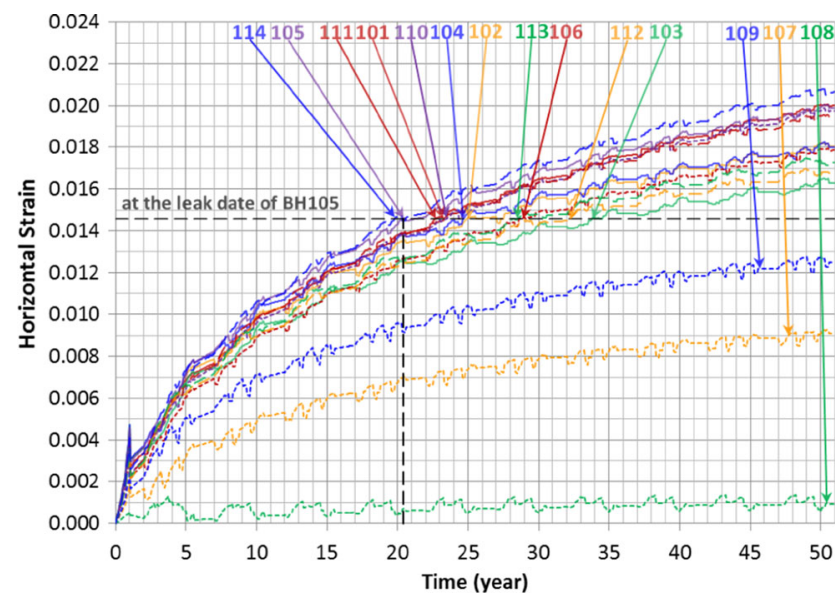

Fig. 15 Predicted horizontal strain in the interbed between Caprock 2 and salt dome above the center of each cavern

moved downward with cavern volume closure due to salt creep.

The direction and magnitude of relative horizontal movement on the salt top above the center of each cavern at 20.42 years simulation time are shown in Fig. 11. Every node above the 14 caverns moves toward Cavern 108 over time. Figure 12 shows the vertical strain in the interbed between Caprock 2 and salt dome above the center of each cavern at 21.25 years simulation time. Figure 13 shows the horizontal strain (the ratio of horizontal displacement of the node on the top of salt dome to vertical distance $(4.3 \mathrm{~m})$ between Caprock 2 bottom and salt dome top) above the center of each cavern at 20.42 years simulation time.

The horizontal strain above Cavern 108 is predicted to be the least (0.0007) because Cavern 108 is located in the middle of 14 caverns. On the other hand, the vertical strain above Cavern 108 is predicted to be the most (0.0084). These imply the well casing of Cavern 108 is relatively safe from horizontal shear failure, while having a higher possibility for vertical tensile failure. The vertical strains 
above Caverns 107, 108, and 109 are larger than the others. The well casings above them may fail by tensile stress. As mentioned in Sect. 1, the casing of BH Well 109B failed at the joint casing (497 m depth) and oil leaked. The cause of failure is probably due to tensile stress created by the downward movement of the salt dome top. Similarly, calculated vertical strain magnitudes suggest that the casings of BH Wells 107 and 108 may also fail by tensile stress in the near future.

Caverns 101, 105, 106, 110, 111, and 114 make up a majority of the outermost caverns. The horizontal strain above Cavern 105 is predicted to be the largest (0.0146), while the vertical strain is predicted to be relatively small (0.0055). The vertical strain above Cavern 101 is predicted to be the least $(0.0036)$, while the horizontal strain is predicted to be relatively large (0.0139). These results imply that the well casings above the outermost caverns have a greater chance of undergoing horizontal shear failure, while being relatively safe from the vertical tensile failure. The horizontal strains above 104, 105 and 114 are larger than the others because Caverns 105 and 114 are far away from the middle of the caverns and Cavern 104 is closest to the fault. The well casings above them may fail by shear stress. As mentioned in Sect. 1, the casing of Well 105B had failed at $499 \mathrm{~m}$ depth and oil leaked. The cause of failure could be shear stress created by the horizontal movement of the salt dome top.

The BH logging results with the Weatherford MultiArm Caliper shows that the casings of 104B, 105B, 106B, $107 \mathrm{~B}, 109 \mathrm{~B}, 111 \mathrm{~B}, 113 \mathrm{~B}$, and 114B are classified as having a high possibility of failure (Wynn 2012) as shown in Fig. 14. The FEM analysis gives similar results. Therefore, we can anticipate what will happen to the well casings in the future from interpreting the analysis results from this study.

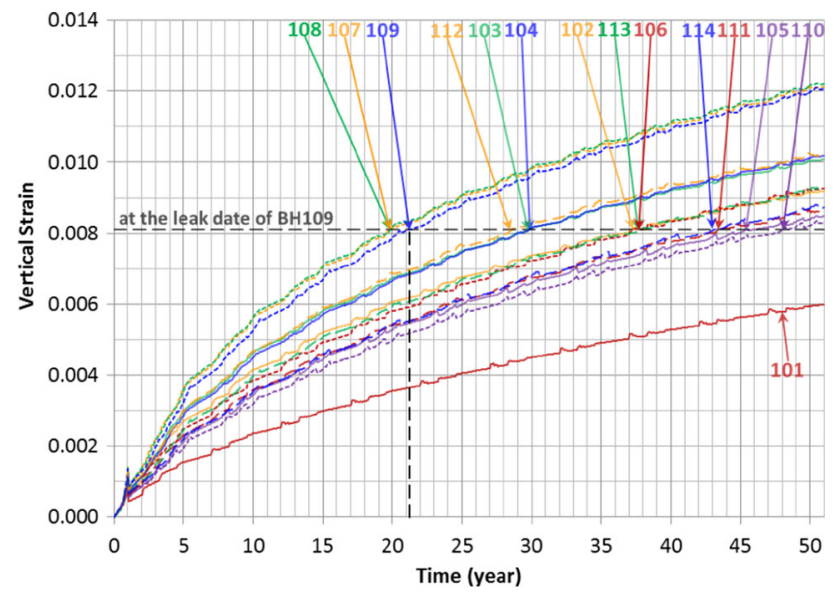

Fig. 16 Predicted vertical strain in the interbed between Caprock 2 and salt dome above the center of each cavern

\subsection{Predictions of Future Response}

Figure 15 shows the horizontal strain above the center of each cavern over time. The well casing of Cavern 105 failed due to shear displacement at 20.42 years (December 3 2009) as mentioned in Sect. 6.1. The horizontal strain was calculated to be 0.0146 when the well casing failed. Therefore, the ratio of 0.0146 can be used as a shear displacement failure limit (dash line in Fig. 15). If this criterion is applicable to all the wells, the well casing of Cavern 114 is predicted to fail by shear strain in the near future, while the well casings of Caverns 112, 109, 107, and 108 are not predicted to fail due to shear displacement until 50 years after the initial leach (calendar year 2040).

Figure 16 shows the vertical strain as a function of time in the interbed between salt dome and Caprock 2 above the center of each cavern. The well casing of Cavern 109 failed due to excessive vertical strain at 21.25 years (October 8 2010) as mentioned in Sect. 6.1. The vertical strain was predicted to be 0.0081 when the well casing of Cavern 109 failed at the joint. Therefore, 0.0081 may be used as a vertical strain failure limit (dash line in Fig. 16). If this criterion is applicable to all the wells, the well casings of Cavern 107 and 108 are predicted to fail in tension due to excess vertical strain in the near future, while the well casing of Cavern 101 is not predicted to fail due to tensile stress until 50 years after the initial leach (calendar year 2040).

\section{Summary and Conclusion}

Oil leaks were found at the well casings of Caverns 105 and 109 in BH SPR salt dome. According to the field observation, damage to the casings occurred at the depth of the interbed between the caprock and salt dome. The causes of the damaged casing segments are a result of vertical and horizontal movements of the interbed between the caprock and salt dome. The salt top subsides because the volume of caverns below the salt top decreases with time due to salt creep closure, while the caprock subsides at a slower rate because the caprock is thick and stiffer. This discrepancy yields a deformation of the well. The deformed wellbore would fail at some time. The oil leak occurs when the wellbore fails.

The nodes on the top of the salt layer move horizontally toward Cavern 108, which is located in the middle of the 14 caverns. The magnitudes of the horizontal movements above the outermost Caverns 101, 105, 106, 110, 111, and 114 are larger than those of the other caverns. Using the horizontal displacement of the failed well of Cavern 105 as a failure criterion applicable to the other wells predicts that the well casing of Cavern 114 is in jeopardy of failing by 
shear stress in the near future. Actually, Wells A and B of BH114 were found to be deformed a lot through the MultiArm Caliper survey (Wynn 2012). Wells A and B were remediated in 2013.

On the other hand, the distances between nodes on the salt top and the caprock bottom above the center of each cavern increase over time. The increased distances above the inner Caverns 107, 108, and 109 are larger than the others. Using the vertical displacement of the failed well of Cavern 109 as a failure criterion applicable to the other wells predicts that the well casings of Cavern 107 and 108 may be in imminent danger of failing by tensile stress due to excessive vertical strain.

A more sophisticated casing model would enable more accurate predictions of failure. For example, the failure models used above are simplistic as each mode (horizontal and vertical strain) is considered separately and based on a very limited sample size. In reality both modes are coupled to influence the strength of the casing. Also, each cavern has two wellbores (Well A and Well B) near the center of each cavern that consist of double steel casings and double cement annuli. The model in this study did not consider the stiffness of the wellbores which would impede the movement of the salt dome top. For a more realistic simulation, two new models need to be constructed. One is a global model which includes representations of the wellbore casings for all the caverns to calculate large-scale displacements. The other is a single-cavern wellbore model to evaluate the effect of those displacements on the as-built casing designs.

Acknowledgments Dr. Courtney G. Herrick (SNL) and Dr. Stephen J. Bauer (SNL) provided a technical review, and Dr. Moo Y. Lee (SNL) and Dr. David J. Borns (SNL) provided a management review. This paper has been improved by these individuals. This research is funded by SPR programs administered by the U.S. Department of Energy. Sandia National Laboratories is a multi-program laboratory operated by Sandia Corporation, a wholly owned subsidiary of Lockheed Martin Corporation, for the U.S. Department of Energy's National Nuclear Security Administration under contract DE-AC0494AL85000

Open Access This article is distributed under the terms of the Creative Commons Attribution License which permits any use, distribution, and reproduction in any medium, provided the original author(s) and the source are credited.

\section{References}

Ballard S, Ehgartner BL (2000) CAVEMAN version 3.0: system for SPR cavern pressure analysis. SAND2000-1751, Sandia National Laboratories, Albuquerque, NM 87185-0750

Butcher BM (1997) A summary of the sources of input parameter values for the WIPP final porosity surface calculations. SAND97-0796. Sandia National Laboratories, Albuquerque
Ehgartner BL (2010a) Big Hill 105 leak analyses. Memorandum from B. Ehgartner to R.E. Myers, DOE SPR PMO dated September 16, 2010. Sandia National Laboratories, Albuquerque

Ehgartner BL (2010b) Ullage losses. Memorandum from B. Ehgartner to R.E. Myers, DOE SPR PMO dated October 27, 2010. Sandia National Laboratories, Albuquerque

Ehgartner BL (2011) Big Hill 109B leak estimate. Memorandum from B. Ehgartner to R.E. Myers, DOE SPR PMO dated February 18, 2011. Sandia National Laboratories, Albuquerque

Ehgartner BL, Bauer S (2004) Large scale salt deformation: comments on subsidence using thermal, creep and dissolution modeling to assess volumetric strain. SAND2004-0095C. Sandia National Laboratories, Albuquerque NM 87185

Ehgartner BL, Sobolik SR (2002) 3-D cavern enlargement analyses. SAND2002-0526. Sandia National Laboratories. Albuquerque, NM 87185-0706

Hoffman EL (1992) Investigation of analysis assumptions for SPR calculations. Memo to JK Linn dated February 7, 1992. Sandia National Laboratories, Albuquerque

Hull J (1988) Thickness-displacement relationships for deformation zones. J Struct Geol 10:431-435

Krieg RD (1984) Reference stratigraphy and rock properties for the Waste Isolation Pilot Plant (WIPP) project. SAND83-1908, Sandia National Laboratories, Albuquerque, NM 87185

Magorian TR, Neal JT (1988) Strategic petroleum reserve (SPR) addition geological site characterization studies Big Hill salt dome, Texas. SAND88-2267. Sandia National Laboratories, Albuquerque

Mohr PJ, Taylor BN, Newell DB (2011) The 2010 CODATA recommended values of the fundamental physical constants (Web Version 6.0). National Institute of Standards and Technology. Gaithersburg, MD 20899. Available: http://physics.nist. gov/constants. Accessed 20 Mar 2011

Munson DE (1998) Analysis of multistage and other creep data for domal salts. SAND98-2276. Sandia National Laboratories, Albuquerque

Park BY, Ehgartner BL, Lee MY, Sobolik SR (2005) Three dimensional simulation for Big Hill strategic petroleum reserve (SPR). SAND2005-3216. Sandia National Laboratories, Albuquerque

Park BY, Herrick CG, Ehgartner BL, Lee MY, Sobolik SR (2006) Numerical simulation evaluating the structural integrity of SPR caverns in the Big Hill salt dome. The 41st U.S. Symposium on Rock Mechanics (USRMS): "50 Years of Rock MechanicsLandmarks and Future Challenges.", held in Golden, Colorado, June 17-21, 2006. ARMA/USRMS 06-924

Rautman CA, Lord AS (2007) Sonar atlas of caverns comprising the US strategic petroleum reserve volume 2: Big Hill site, Texas. SAND2007-6023. Sandia National Laboratories, Albuquerque

Shipton ZK, Soden AM, Kirkpatrick JD, Bright AM, Lunn RJ (2006) How thick is a fault? Fault displacement-thickness scaling revisited. In Abercrombie, R. (Eds) Earthquakes: Radiated Energy and the Physics of Faulting, AGU, pp. 193-198

Wawersik WR, Zeuch DH (1984) Creep and creep modeling of three domal salts-a comprehensive update. SAND84-0568. Sandia National Laboratories, Albuquerque

Wynn K. (2012) 00-0000-2011-01-01-UPDATED MULTI ARM CALIPER SURVEYS.xlsx. MS Excel 2010 file. Compilation of SPR caliper survey data. DM Petroleum Operations. US Strategic Petroleum Reserve, New Orleans 